Çukurova Üniversitesi Mühendislik Mimarlık Fakültesi Dergisi, 33(4), ss. 133-146, Aralık 2018

Çukurova University Journal of the Faculty of Engineering and Architecture, 33(4), pp. 133-146, December 2018

\title{
Kısmen Batık Bir Bariyerin Su Dalgaları ile Etkileşiminin Açık Kaynaklı Hesaplamalı Akışkanlar Dinamiği ile İncelenmesi
}

\author{
Erdem KAYA ${ }^{1}$, Utku ŞENTÜRK ${ }^{* 1}$ \\ ${ }^{1}$ Ege Üniversitesi, Mühendislik Mimarlık Fakültesi, Makina Mühendisliği Bölümü, İzmir
}

Gelis tarihi: 09.01.2018～Kabul tarihi: 25.12.2018

\section{$\ddot{O} z$}

Bu çalışmada, düşey, düzlemsel ve rijit bir bariyerin, sabit genlik ve frekansa sahip su dalgaları ile etkileşimi problemi ele alınmıştır. Öncelikle problemin lineer dalga teorisi altında analitik çözümüne ilişkin yöntem verilmiştir. Daha sonra bir açık kaynaklı hesaplamalı akışkanlar dinamiği yazılımı olan OpenFOAM kapsamındaki modüller aracılığıyla problemin sayısal çözümü gerçekleştirilmiştir. Ön aşama olarak, iki boyutlu sayısal dalga kanalı testleri ile, bu modüllerin dalga oluşturma ve sönümleme gibi özellikleri sınanmıştır. Analitik çözümlere kıyasla görülen en yüksek hata \%1 olarak bulunmuştur. Belirlenen ağ ve çözücü özellikleri, batık bariyer probleminin modellenmesinde kullanılmış̧ır. Bariyerden yansıyan ve üreteçten çıkan dalgalar, lineer dalga teorisine dayalı olarak ayrıştırılmış, böylece yansıma ve iletilme katsayıları hesaplanmıştır. Çeşitli dalga frekansları için bulunan sonuçlar, hem analitik çözümle hem de literatürde yer alan deneysel sonuçlarla karşılaştırmalı olarak değerlendirildiğinde, nicel ve nitel olarak yüksek uyum yakalandığı görülmüştür. Ayrıca, viskozite etkilerinin de hesaba katılmasıyla, lineer teoride ihmal edilen enerji kayıpları da belirlenmiş; bu kayıpların başlıca nedeninin bariyer ucundaki çevri oluşumu olduğu görülmüştür. Bir kısmen batık bariyer uygulaması olan salınan su sütunu ön duvarındaki enerji kayıplarının, salınan su sütunu hidrodinamik verimi üzerindeki etkisi tartışılmıştır.

Anahtar Kelimeler: Su dalgaları, Lineer dalga teorisi, Hesaplamalı akışkanlar dinamiği, OpenFOAM

\section{Investigating the Interaction of a Partially Submerged Barrier with Water Waves Using Open-Source Computational Fluid Dynamics}

\begin{abstract}
The interaction of a vertical, flat, rigid barrier with monochromatic water waves of constant amplitude is considered in this study. The method for the analytical solution to the problem under the assumptions of linear wave theory is introduced. This is followed by the numerical solution to the problem using the modules under the open-source computational fluid dynamics code OpenFOAM. As an initial stage, twodimensional, numerical wave flume tests are carried out where the wave generation and absorbing features are tested. Maximum error relative to analytical solutions is found to be $1 \%$. Grid and solver properties to be used for the submerged barrier problem are determined at this stage. The reflected and incident wave signals are decomposed with an approach based on the linearized theory. Results obtained
\end{abstract}

*Sorumlu yazar (Corresponding author): Utku ŞENTÜRK, utku.senturk@ege.edu.tr 

Incelenmesi

for several frequencies are found to be in good agreement with the analytical computations performed here and the experimental results obtained by other researchers. Taking the viscosity effects into account, the amount of energy loss which is neglected in the linearized thory is computed. The vortex formation at the tip is found to be the primary reason for this loss. Effects of the energy losses of the oscillating water column front wall which is a partially submerged barrier application, on the the oscillating water column hydrodynamic efficiency are investigated.

Keywords: Water waves, Linear wave theory, Computational fluid dynamics, OpenFOAM

\section{GİRIŞ}

Su dalgalarının cisimlerle etkileşimini içeren problemler, hidrodinamik alanında sıkça ele alınmaktadırlar. Şüphesiz bunun başlıca sebebi, çeşitli kabuller altında ve uygun matematiksel araçlar ile analitik çözümlerinin yapılabilmesidir. $\mathrm{Bu}$ kapsamda yer alan, kısmen batık bir bariyerin su dalgaları ile etkileşimi de, analitik çözümü mevcut olan nadir hidrodinamik problemlerinden biridir. Böylesi temel bir problemin çözümü ile elde edilen sonuçlar, çok çeşitli mühendislik uygulamalarına 1 şı tutarlar.

Bu tip bir dalga-yapı etkileşimine, bir yenilenebilir enerji kaynağı olan dalga enerjisinden yararlanmak üzere tasarlanmış sistemlerde rastlanır. Buna örnek olarak, salınan su sütunu verilebilir $[1,2]$. Salınan su sütunu (Şekil 1), denize kısmen batırılmış ve tabanı açık bir basınç odası olarak düşünülebilir. Oda içindeki su seviyesi, dalga hareketinden ötürü yükselip alçalır ve oda içindeki havayı bir piston gibi sıkıştırır. Odanın üzerine, atmosfere açılan bir kanal yerleştirilir ve buraya bir hava türbini konursa, kanaldaki hava hareketinden elektrik enerjisi elde edilebilir.

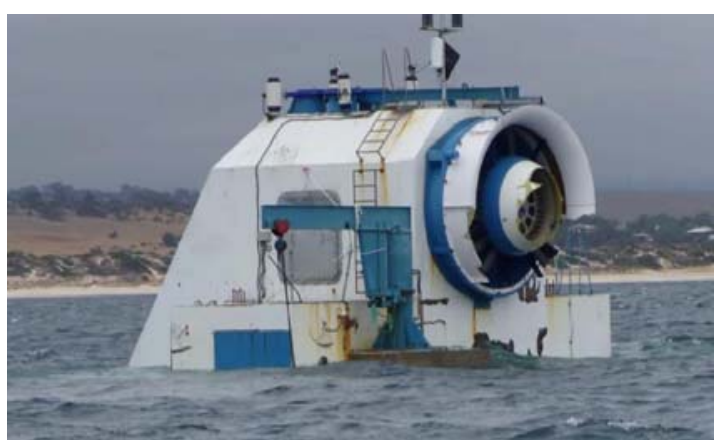

Şekil 1. Salınan su sütunu tipi dalga enerjisi dönüştürücü [3]
Salınan su sütunu veriminin dalga frekansına göre değişimi analitik $[1,2]$ ve deneysel [4,5] çalışmalarla incelenmiştir. Bu çalıșmalarda salınan su sütunu hidrodinamik verimi $\eta$ 'nin, birimsiz dalga sayısı Kh'a göre değişimi Şekil 2'deki gibi verilmiştir. Analitik çalışmada ideal ve dönümsüz akış kabulleri yapılarak sürtünme, girdap oluşumu ve akış ayrılması gibi sebeplerden doğan enerji kayıpları ihmal edildiği için deneysel çalışmalarda görülen hidrodinamik verimlerin analitik çalışmaya göre daha düşük olduğu görülmektedir.

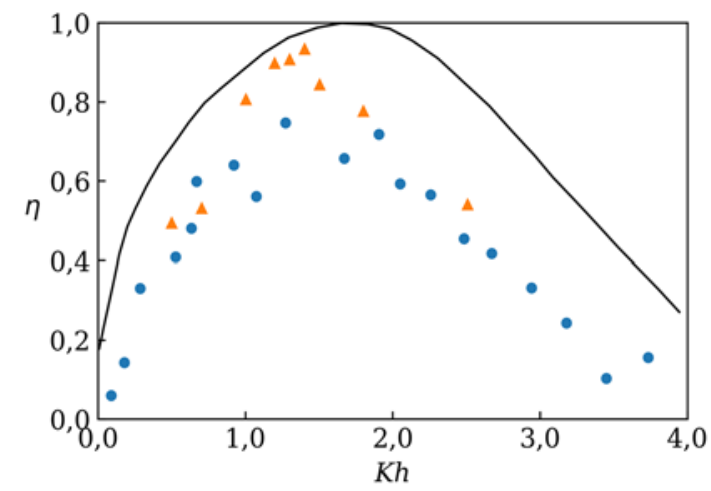

Şekil 2. Salınan su sütunu hidrodinamik verim eğrisinin analitik [1] ve deneysel [4, 5] karşılaştırılması

Yapıdaki enerji kayıplarının temelinde yayılım ve saçılım adı verilen iki temel hidrodinamik etki bulunmaktadır. Enerji dönüşümünü sağlayacak mekanik bir yapının hacim içerisinde oluşturacağ basınç dağılımı kaynaklı dalga oluşumu, yayılım problemini ortaya çıkmaktadır. Daha basite indirgenerek, mekanik yapı dalga üreteci görevini görmektedir denilebilir. Dalga saçılımı problemi ise, ilerleyen dalgalar ile salınan su sütunu yapısının etkileşiminden ibarettir. Yapıdan gerçekleşen saçılım, bariyerdeki yansıma 
problemine benzer şekilde ilerleyen dalga yönündeki dalga iletimi ve zit yöndeki dalga yansımasından oluşmaktadır. Salınan su sütununun analitik hesaplamalarında yayılım ve saçılım problemleri birbirinden ayırt edilebilmektedir. Buna karşın, deneysel çalışmalarda bu iki problemi birbirlerinden ayırmak oldukça zordur.

Salınan su sütunu problemi deneysel çalışmalarla olduğu gibi, sayısal olarak da bütünüyle ele alınabilmektedir. Salınan su sütunu problemindeki geometrik değişkenleri sayısal olarak inceleyen [6,7] hidrodinamik verimde iyileştirmeler gerçekleştirebilmişlerdir. Enerji kayıplarının dalga frekanslarına bağlı olarak değiştiği çalışmalardan görülmektedir, ancak yine de enerji kayıpları söz konusudur ve bu çalışmalarda enerji kayıpları bir bütün olarak ele alınmıştır. Salınan su sütunu yapısındaki bariyer kaynaklı enerji kayıplarının büyüklüğü literatürde daha önce incelenmemiştir.

Salınan su sütununun ön duvarı, kısmen batık bir bariyer olup, makinanın enerji verimliliğinde önemli etkiye sahip bir bileşendir. Bu ön duvarın suya batıklık miktarına bağlı olarak makinanın optimum verime sahip olduğu dalga frekansının değiştiği bilinmektedir [1,2].

Batık bariyer-dalga etkileşimi problemi, lineer dalga teorisi altında birçok kez ele alınmış ve farklı matematiksel yöntemler ile analitik çözümü gerçekleştirilmiştir [8-11]. Böylece, su içindeki hız ve basınç, bariyerin maruz kaldığı kuvvetler, iletilen ve yansıyan dalga genlikleri gibi birçok önemli mühendislik parametresi hesaplanabilmektedir. Bu analitik çözüm, düşey ve düzlemsel bir bariyer geometrisi için söz konusu olup, dönümsüz akışkan tanımına uyan su içerisinde çok küçük genlikli dalgaların ilerlediği kabulüne dayalıdır. Lineer dalga teorisine ait bu kabullerin dışında, ya da, karmaşık geometriye sahip bir yapının dalgalar ile etkileşimi halinde, sözü edilen analitik çözüm yapılamaz. Bu durumda genellikle, deneysel yöntemlere başvurulmakta olup, hesaplamalı akışkanlar dinamiği (HAD) araçlarının kullanımının giderek arttığı görülmektedir [12-14].
Günümüzde HAD araçları gerek akademik gerekse endüstriyel birçok problemin çözümünde başarıyla kullanılmaktadır. Bunlar arasında yer alan ticari yazılımlar, ülkemizde de sıkça tercih edilmektedirler. Son yıllarda bunlara alternatif olarak kullanılan ve giderek önem kazanan açık kaynaklı HAD araçları göze çarpmaktadır. Bunlardan başlıcası, OpenFOAM (Open Source Field Operation and Manipulation) yazılımıdır. Kısaca OpenFOAM, akışkan hareketi denklemleri gibi kısmi diferansiyel formdaki denklemleri, sonlu hacimler yöntemine dayalı olarak çözen, herhangi bir ticari lisans gerektirmeyen, $\mathrm{C}++$ dilinde geliştirilmiş açık kaynaklı bir yazılımdır. $\mathrm{Bu}$ sayede, yazılımın kaynak kodu dilendiği gibi değiştirilebilmekte, amaca uygun olarak düzenlenerek yeni çözücüler elde edilebilmektedir. Yakın dönemde, özellikle gemi hidrodinamiği alanında OpenFOAM uygulamalarının arttığ1 görülmektedir. [12, 15]. Bu kapsamda geliştirilen modüllerin genel dalga-yapı etkileşimlerinde kullanılmak üzere sinanması ve mevcut araştırmalarda kullanılabilir hale getirilmesi, yerli alternatif çözüm araçları sağlanması açısından önemlidir.

$\mathrm{Bu}$ kapsamda mevcut çalışmanın amacı, kısmen batık, düşey, düzlemsel ve rijit bir bariyerin, sabit genlik ve frekansa sahip su dalgaları ile etkileşiminin, OpenFOAM kullanılarak modellenmesidir. Sayısal çözüm, mevcut analitik çözüm ile karşılaştırmalı olarak değerlendirilecektir. Öncelikle, laboratuvar ortamındaki dalga kanalı deneylerine benzer şekilde, bir sayısal dalga kanalı modellenecek ve lineer dalga teorisine dayalı kontrol edilen bir dalga üretecinin doğruluğu sınanacaktır. Daha sonra, sayısal dalga kanalı içerisine kısmen batık bariyer geometrisi yerleştirilecek, çeşitli dalga frekansları için çözümler yapılacaktır. Bariyerden aktarılan ve yansıyan dalga genliği (enerjisi) değerleri başta olmak üzere, çeşitli parametreler analitik çözümler ve literatürden alınan deneysel sonuçlar ile karşılaştırılacaktır. Çalışmada saçılım probleminde bariyer kaynaklı enerji kayıpları incelenerek, kısmen batık bariyer çevresindeki enerji kayıplarının salınan su sütunu hidrodinamik verimi üzerindeki etkisi ortaya koyulacaktır. 
Kısmen Batık Bir Bariyerin Su Dalgaları ile Etkileşiminin Açık Kaynaklı Hesaplamalı Akışkanlar Dinamiği ile Incelenmesi

\section{PROBLEMIN TANIMI}

Salınan su sütununda bahsedilen yayılım problemini ihmal edebilmek için Şekil 3a'daki salınan su sütununun mekanik unsurları kaldırılabilir ve Şekil 3b'de verilen gösterime dönüşebilir. $\mathrm{Bu}$ durum saçılım problemindeki enerji kayılarının incelenebilmesine olanak sağlayabilir. Burada sabit su derinliğine $(h)$ sahip bir kanalda, $+x$ yönünde ilerleyen belirli bir genliğe $(A)$ sahip su dalgaları ile yapılardan yansıyan dalgaların girişimi gerçekleşmektedir. Salınan su sütunu derinliği $(b)$ ve bariyerin su içerisinde kalan kısmı (a) olarak ifade edilmektedir.

Salınan Su Sütunu

(a)
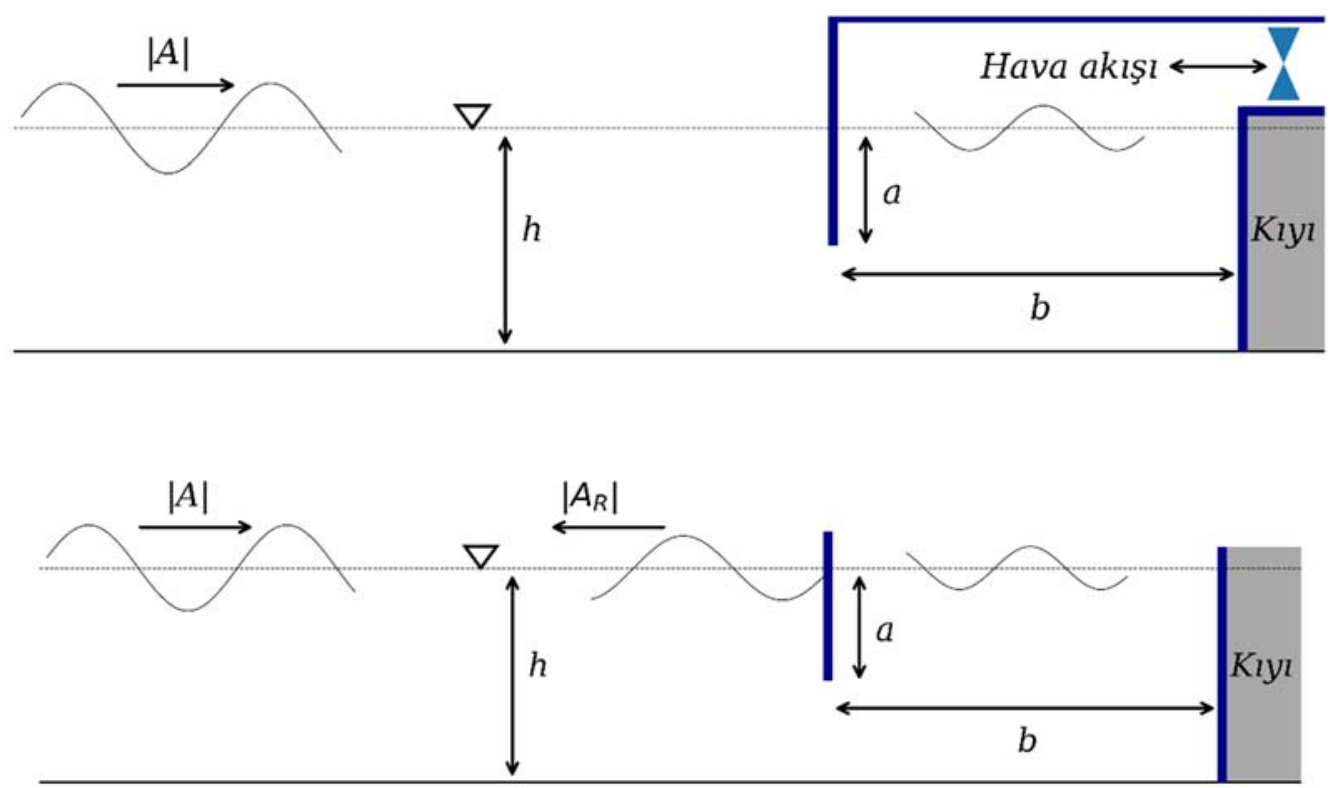

(b)

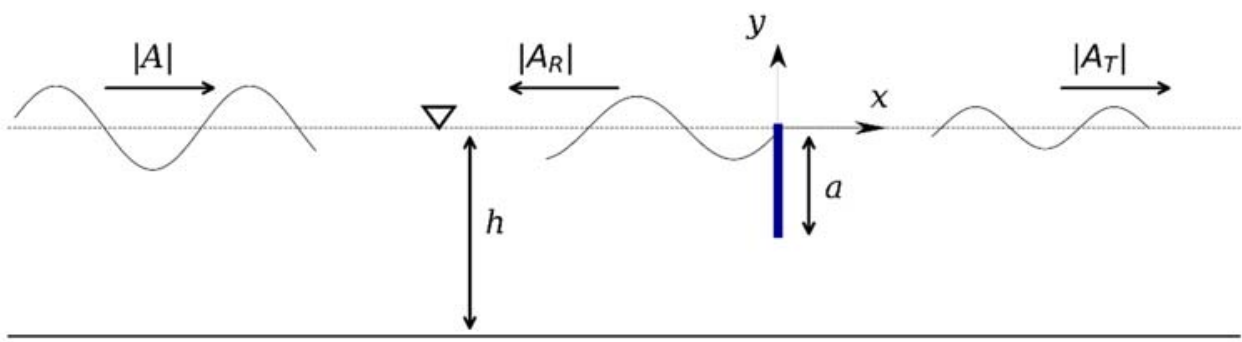

(c)

Şekil 3. (a) Salınan su sütunu, (b) Saçılım problemi ve (c) Kısmen batık bariyer şematik gösterimleri

Saçılıma neden olan yapılar, bariyerden çok uzaklaştırılarak bariyer yalnız bırakılır ve problem Şekil 3c'deki gösterime dönüşür. Burada, ilerleyen dalgalar kısmen batık, düşey, düzlemsel ve rijit bir bariyere çarpmakta, dalgaların bir kısmı bariyerden yansırken, bir kısmı ise bariyerin altındaki boşluktan $+x$ yönüne iletilmektedir. Her iki problemin başlıca parametreleri, yansıyan $\left(A_{R}\right)$ ve iletilen $\left(A_{T}\right)$ dalgaların genlikleridir. 
Sabit frekanslı ve küçük genlikli dalgalar için geçerli lineer dalga teorisi ele alındığında dalga potansiyelinin (Eşitlik 1),

$$
\phi(x, y)=-\frac{i g A}{\omega} \frac{\cosh k(y+h)}{\cosh k h} e^{i k x}
$$

serbest su yüzeyi denkleminin (Eşitlik 2) de,

$\eta(x)=A e^{i k x}$

olduğu bilinmektedir $[16,17]$. Burada $\phi$ ve $\eta$, kompleks değerli fonksiyonlardır. Eşitliklerde dalga sayısı $k$, genlik $A$, yerçekimi ivmesi $g$ ve açısal frekans $\omega$ ile gösterilmiştir. Su içerisinde bariyer olması halinde genel çözüm (Eşitlik 3a ve 3b),

$$
\begin{aligned}
\phi_{1}=\left(e^{i k x}\right. & \left.+R e^{-i k x}\right) \psi_{0}(y) \\
& +\sum_{n=1}^{\infty} A_{n} e^{k_{n} x} \psi_{n}(y), \quad x<0 \\
\phi_{2}=T e^{i k x} & \psi_{0}(y) \\
& +\sum_{n=1}^{\infty} B_{n} e^{-k_{n} x} \psi_{n}(y), \quad x>0
\end{aligned}
$$

olarak yazılır $[11,17] . \mathrm{Bu}$ eşitlikler, bariyerin yukarı akım ve aşağı akım tarafındaki bölgeler için ayrı ayrı yazılmış potansiyel fonksiyonlardır. Toplam sembolleri altındaki terimler, bariyer civarında görülen yerel dalga modlarını ifade ederler. $\mathrm{Bu}$ modlar bariyerden uzaklaştıkça kaybolurlar [8]. Eşitlik 8a'nın sağ tarafındaki ilk terim, $x=-\infty$ 'dan bariyere gelen dalgaları temsil eden kısımdır. $R$ ve $T$ terimleri ise, yansıyan ve iletilen dalgaların kompleks genlikleri $A_{R}$ ve $A_{T}$ ile (Eşitlik 4 ve 5),

$$
\begin{aligned}
& R=A_{R} / A \\
& T=A_{T} / A
\end{aligned}
$$

uyarınca ilişkilidirler. Dolayısıyla bunlar, boyutsuz dalga genlikleridir. Birim dalga genişliğinde mevcut dalga gücü,
$W=\frac{1}{2} \rho g|A|^{2}\left[\frac{1}{2} \frac{\omega}{k}\left(1+\frac{2 k h}{\sinh 2 k h}\right)\right]$

Eşitlik 6 ile ifade edilir [17]. Buna göre, enerjinin korunumu gereği (Eşitlik 7),

$|R|^{2}+|T|^{2}=1$

eşitliğinin sağlandığı görülebilir. Eşitlik $3 \mathrm{a}$ ve 3 b'de görülen $\psi_{n}(y)$ ise, problemin analitik çözümüne ilişkin ortonormal fonksiyon seti olarak ifade edilmektedir $[11,17]$. $R$ ve $T$ katsayılarının dalga frekansına bağlı değişimlerinin bulunması için, literatürde çok çeşitli yöntemler mevcuttur [8-11]. Bu katsayılar Porter [11] tarafindan verilen eşleştirilmiş özfonksiyon açılımları yöntemi kullanılarak bulunacaktır. Kisaca bu yöntemde, Eşitlik $3 \mathrm{a}$ ve $3 \mathrm{~b}$ ile verilen potansiyel fonksiyonlar, bariyer düzlemi olan $x=0$ ' da eşleştirilir ve bunlara bariyer sınır koşulları uygulanır. Ortonormal fonksiyonların ortogonalliğinden yararlanılarak, $N$ adet katsayı için $N$ adet eşitlik elde edilir ve bu sistem çözülerek Eşitlik 3a ve 3b'deki bilinmeyen katsayilar bulunur [8-11].

\section{HAD DENKLEMLERI}

HAD simülasyonlarında, OpenFOAM ortamında geliştirilmiş waves 2 Foam adlı çözücü kullanılmıştır. waves 2 Foam, birbirine karışmayan akışkanlardan ibaret çok fazlı sistemler için geliştirilmiş akışkan hacmi (volume of fluid) yöntemine dayalı bir çözücüdür. OpenFOAM'da halihazırda bulunan interFoam adlı çözücüden türetilmiştir [12, 19]. Simülasyonlarda çözülen temel denklemler (Eşitlik 8-10), sıkıştırılamaz akış için,

$\nabla \cdot \mathbf{V}=0$

$\frac{\partial \mathbf{V}}{\partial t}+\nabla \cdot(\mathbf{V V})=-\nabla p+\nabla \cdot(v \nabla \mathbf{V})+\mathbf{g}$

$\frac{\partial \alpha}{\partial t}+\nabla \cdot(\alpha \mathbf{V})=0$ 
olarak yazılırlar. Burada $p$, statik basıncın yoğunluğa bölünmesi ile bulunan kinematik basınç ve $g$ ise yerçekimi vektörüdür. $\alpha$ ile gösterilen faz indikatörü, akış bölgesinin herhangi bir hücresindeki su hacminin, hücrenin toplam hacmine oranıdır. Buna göre $\alpha$ 'nın değeri su içinde 1 ve hava içinde 0 iken, hava - su arayüzeyinde $(0,1)$ aralığındadır. Yoğunluk ve kinematik viskozite gibi akışkan özellikleri (Eşitlik 11 ve 12),

$\rho=\alpha \rho_{s u}+(1-\alpha) \rho_{\text {hava }}$

$v=\alpha v_{s u}+(1-\alpha) v_{\text {hava }}$

şeklinde, faz indikatörüne bağlı süreksiz fonksiyonlar olarak tanımlıdırlar. Eşitlikler sonlu hacimler yöntemine dayalı ayrıklaştırılmışlar ve PISO (Pressure Implicit with Splitting of Operators) adlı basınç düzeltme algoritması ile çözülmüşlerdir.

waves 2 Foam, iki veya üç boyutlu sayısal dalga tanklarının simülasyonu için özelleşmiş bir araç olup, çeşitli dalga modellerine dayalı dalga üreteci tiplerine sahiptir. Buna göre, problem bölgesinin dalga üreteci olarak tayin edilen sınır koşulunda hızlar tanımlanarak, arzu edilen tipte dalgalar oluşturulabilmektedir. Lineer dalga teorisi için bu hızlar, Eşitlik 1 ile verilen potansiyel fonksiyonun tanımı gereği, $(u, v)=(\partial \phi / \partial x, \partial \phi / \partial y)$ ile bulunurlar. Ayrica waves 2 Foam bünyesinde, sonlu uzunluğa sahip sayısal dalga kanalının uçlarında oluşacak istenmeyen yansımaları engellemek için rahatlatma bölgeleri tanımlanabilmekte, bu bölgelerde filtreleme ve sönümleme yapılabilmektedir. Bunun için, Şekil 4'te gri renkli görülen rahatlatma bölgelerinde (Eşitlik 13),

$$
F=\alpha_{R} F_{\text {hesap }}+\left(1-\alpha_{R}\right) F_{\text {hedef }}
$$

uygulanır. Burada $F, u, v$ veya $\alpha$ 'nın herhangi birini temsilen yapılmış bir kısaltmadır. Eşitlik 14'teki $\alpha_{R}$ ise, $x_{R}$ bölgenin uzunluğu olmak üzere,

$\alpha_{R}\left(x / x_{R}\right)=1-\frac{\exp \left[\left(x / x_{R}\right)^{3.5}\right]-1}{\exp (1)-1}$ olarak tanımlanmış bir rampa fonksiyonudur [15] (Şekil 4). Örneğin, bir sayısal dalga kanalı simülasyonunun herhangi bir anı ele alınsın. $F_{\text {hesap }}$, Şekil 4'te gri renkli bölgelerde HAD çözümünden bulunan $u, v$ ve $\alpha$ değerlerine karşılık gelmektedir. $F_{\text {hedef }}$ ise, her bölgede farklıdır. Kanalın üreteç tarafindaki rahatlatma bölgesinde $\left(\mathrm{RB}_{1}\right), F_{\text {hedef }}$, lineer dalga teorisinden bulunan ve $+x$ yönünde ilerleyen dalgalara ait çözümdür. Yani, bariyerden yansıyıp tekrar üretece ulaşan dalgalar, bu bölge içinde filtrelenip sönümlenir. Böylece, bunların üreteçten yansıyıp tekrar bariyere gitmeleri önlenir. Kanalın diğer ucunda $\left(\mathrm{RB}_{2}\right), F_{\text {hedef }}$ yerine hızlar için $u=v=0$ yazılır. Faz indikatörü $\alpha$ ise kanalın sakin su seviyesi $y=0$ 'ın altında su ve üstünde hava olacak şekilde değerler alır. Böylece seçili bölge, bariyerden geçip bu uca ulaşan su dalgalarını tamamen sönümleyen yapay bir kıyı görevi görür.
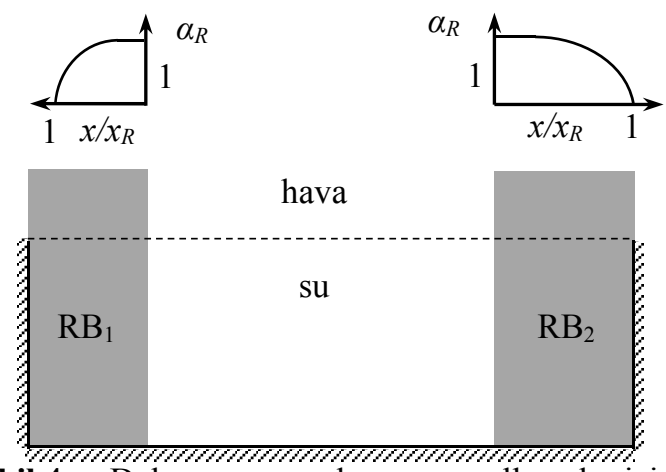

Şekil 4. Dalga yansımalarını engellemek için oluşturulan rahatlatma bölgeleri

Kisaca, rahatlatma bölgeleri sayesinde, probleme ait büyüklüklerin harmonik rejime girdikleri andan itibaren, $x>0$ için, yalnızca bariyerden iletilen dalgalar görülecektir. $x<0$ için ise, üreteçten çıkan dalgalar ve bariyerden yansıyan dalgaların girişimi mevcut olacaktır. Artık dalga yüksekliğinin seçilen konumlardaki anlık değerleri kaydedilebilir. Bu veriler ile $|T|$ doğrudan belirlenebilir (Eşitlik 5). Ancak yansıyan dalgalar, üreteçten gelen dalgalar ile girişim halinde bulundukları için $|R|$ doğrudan belirlenemez. Girişim halindeki dalgaların ayrıştırılması için çeşitli yöntemler önerilmiş olup burada, Dean ve Dalrymple [16] tarafindan sunulan yöntem kullanılacaktır. $\mathrm{Bu}$ yöntemde, su yüzeyi formu $H(x, t)$, bir periyotluk zaman dilimi 
boyunca $N$ defa kaydedilerek tek bir grafik üzerinde toplanır (Şekil 5). Bu grafikte görülen en büyük ve en küçük genlik ( $A_{\max }$ ve $A_{\min }$ ) okunarak yansıyan dalga genliği (Eşitlik 15)

$$
\left|A_{R}\right|=\frac{A_{\max }-A_{\min }}{2}
$$

ile bulunabilir. Ayrıca, yine bu veriler (Eşitlik 16),

$|A|=\frac{A_{\max }+A_{\min }}{2}$

ile hesaplanarak üreteçten çıkan dalga karakteristiklerinin kontrolü yapılabilir. $\mathrm{Bu}$ iki genliğin oranı da $|R|$ katsayısını verecektir.

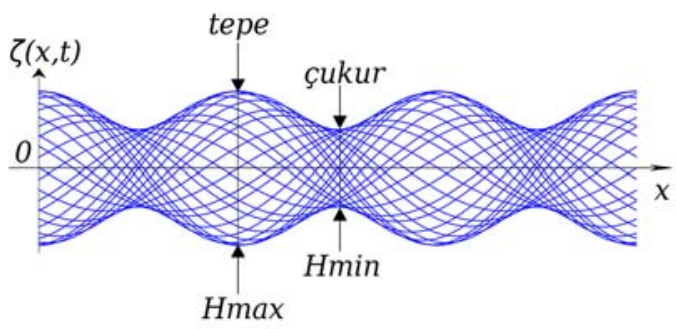

Şekil 5. Bir periyot için üst üste bindirilen dalga örgüsünün şematik gösterimi

\section{BULGULAR}

Çalışmanın ilk aşamasında, OpenFOAM yazılımı ile lineer su dalgalarının modellenmesi üzerinde doğrulama testleri yapılmıştır. Daha sonra dalgabariyer etkileşimi problemi ele alınmıştır. Tüm incelemelerde, suyun ve havanın kinematik viskozite değerleri $v_{s u}=1 \times 10^{-6} \mathrm{~m}^{2} / \mathrm{s} \quad$ ve $v_{\text {hava }}=1,48 \times 10^{-5} \mathrm{~m}^{2} / \mathrm{s}$ olarak sabit alınmış ve akış laminer kabul edilmiştir. Dalga frekansı, dalga sayısı $(k)$ aracılığıyla değiştirilmiştir. Dalga yüksekliği, lineer dalga teorisi için dalga eğiminin üst sınırı [18] gözetilerek her bir frekans için ayrıca hesaplanmış ve kulllanılmıştır. Tüm simülasyonlarda, zaman integrasyonu için örtülü Euler yöntemi uygulanmıştır. Ayrıca, taşınım terimleri için ikinci mertebeden akışyönü (upwind) düzeni, basınç ve difüzyon terimleri için ise hücreler arası doğrusal değişim kabulü kullanılarak ayrıklaştırma uygulanmıştır. Elde edilen doğrusal denklem sistemlerinin iteratif çözümünde, hız, basınç ve faz indikatörü için toleranslar $10^{-9}, 10^{-7}$ ve $10^{-7}$ alınmıştır. Zaman adımı için bir ön çalışma yapılmış ve $\Delta t=T / 1500$ olarak belirlenmiştir. Ard işlemlerde görselleştirmeler, Python programlama dili bünyesindeki modüller ile yapılmıştır.

\subsection{Sayısal Dalga Kanalı Testi}

Çalışmada öncelikle, waves2Foam çözücüsünün dalga oluşturma ve sönümleme becerileri test edilmiştir. Dolayısıyla bu problemde bariyer olmayıp, kanalın bir ucundaki üreteçten çıkan dalgalar, kanalın diğer ucundaki rahatlatma bölgesinde sönümlenmiştir. $\mathrm{Bu}$ bölümde birimsiz dalga sayısının $(k h) \quad 0,8$ olduğu dalga frekansı incelenmiştir.

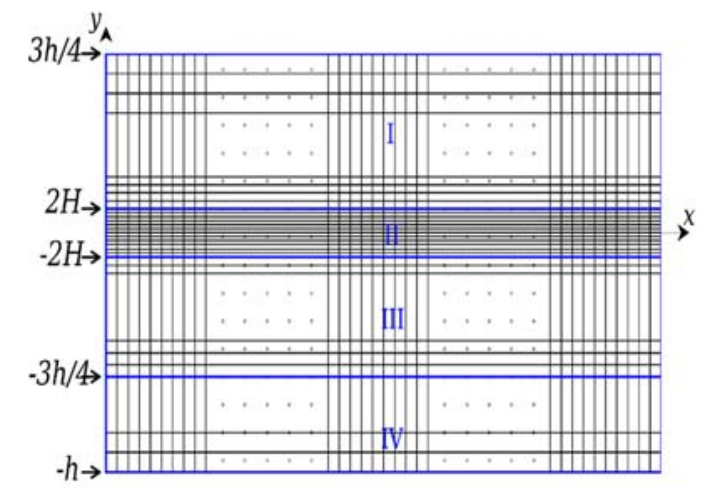

Şekil 6. Sayısal dalga kanalı ağ örgüsü

$\mathrm{Bu}$ aşamada öncelikle ağ çözünürlüğünün hesaplamalara etkisi incelenmiştir. Hesaplama bölgesi Şekil 6'daki gibi dört farklı bloğa ayrılmış, su ve hava fazlarının etkileşime girdiği bölge olan Blok II temel alınarak dört ağ çözünürlüğü test edilmiş olup, en düşük çözünürlükte, bir dalga boyunda 18 hücre ve bir dalga yüksekliğinde 2,25 hücre bulunmaktadır. Eleman sayıları her yönde ikiye katlanarak diğer üç çözünürlük elde edilmiştir. Böylece dört farklı ağ, $18 \times 2,25,36 \times 4,5$, $72 \times 9$ ve $144 \times 18$ olarak ifade edilebilir. Blok II'de elde edilen yap1 dikeyde 1,02-1,05 büyüme oranlarıyla süpürülerek diğer blokların ağ örgüleri oluşturulmuştur. 
Kısmen Batık Bir Bariyerin Su Dalgaları ile Etkileşiminin Açık Kaynaklı Hesaplamalı Akışkanlar Dinamiği ile Incelenmesi

Şekil 7'de görüldüğü üzere, özellikle $72 \times 9$ ve $144 \times 18$ için eğrilerin uyumu çok iyi bulunmuş olup dalga genlikleri arasındaki en yüksek bağıl hata \%1 olarak hesaplanmıştır (Şekil 8a). Bu iki dalga sinyalinde, analitik çözüme kıyasla en yüksek faz kayması \%0,5 olarak bulunmuş̧ur (Şekil 8b). Bu durum, sonuçlarda faz kayması probleminin ihmal edilebilir düzeyde olduğunu göstermiştir. Sonuçlar göz önünde bulundurularak dalga-bariyer incelemelerine $72 \times 9$ çözünürlüğü ile devam edilmiş̧ir. Çalışmada, analiz edilen farklı dalga özelliklerine göre az miktarda değişim gösterse de, yaklaşık olarak 200.000 hücre kullanılmıştır.

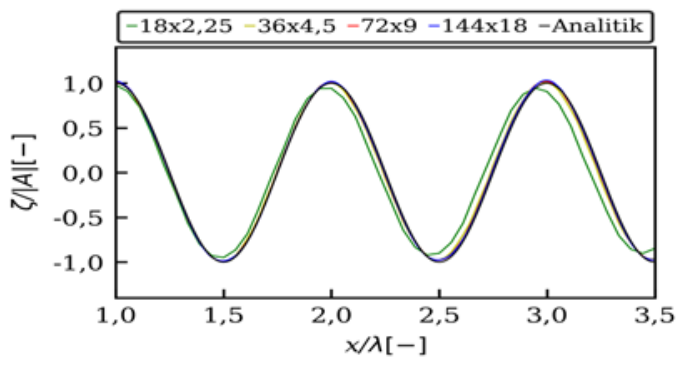

Şekil 7. Ağ çözünürlüğünün serbest su yüzeyi formuna etkisi
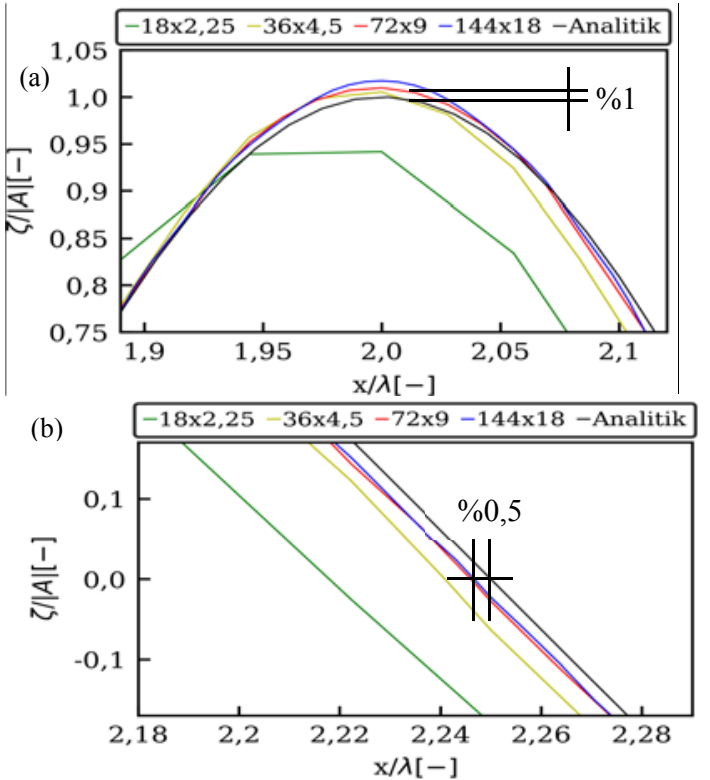

Şekil 8. Farklı ağ çözünürlükleri için bağıl hata: (a) Dalga genliği (b) Faz kayması
Rahatlatma bölgesindeki yansıma etkilerinin ne ölçüde engellendiği de bu bölümde sınanmıştır. Şekil 4'te görülebilen $x_{R, R B I}=\lambda$ ve dalgaların serbeste geliştiği orta bölgenin uzunluğu $7 \lambda$ olacak $x_{R, R B 2}$ uzunluğu değiştirilerek rahatlama bölgesi sönümleme kabiliyeti incelenmiştir. Şekil 9a ve Şekil 9b'den görülebileceği gibi, $x_{R, R B 2}=5 \lambda$ değerinde eğrilerin uyumunun oldukça yeterli olduğu görülmektedir.
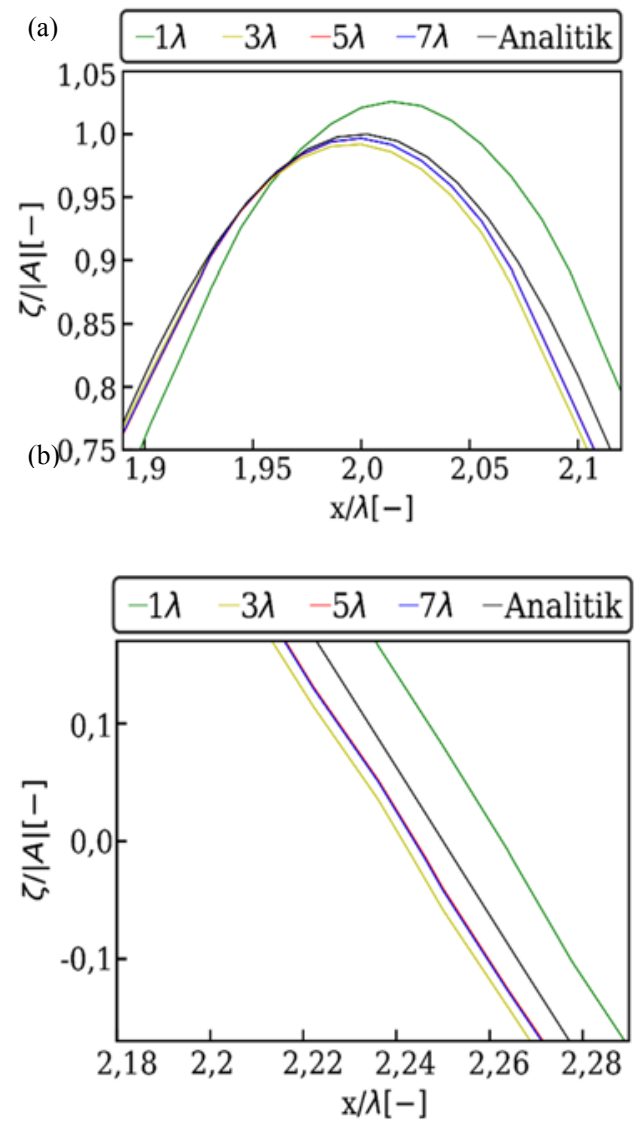

Şekil 9. Farklı $x_{R, R B 2}$ değerleri için bağıl hata: (a) Dalga genliği (b) Faz kayması

Şekil 10'da, her iki çözümden elde edilen hız alanları, $t=30 T$ anında görülmektedir. Hızlar, serbest yüzey civarında yüksek değerlere sahip olup derinlere inildikçe süratle azalırlar. $\mathrm{Bu}$ yüzden serbest yüzey civarındaki değerler şekilde verilmiştir. Sonuçların genel olarak yüksek uyuma sahip oldukları görülmektedir. 


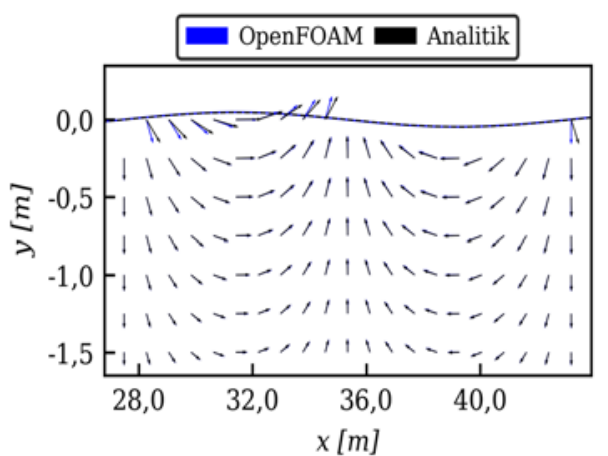

Şekil 10. Su içindeki hızların karşılaştırılması

Son olarak kanaldaki serbest su yüzeyinin formu, $t=30 T$ anı için lineer dalga teorisi çözümü ile karşılaştırmalı olarak Şekil 11'de verilmiştir. Ayrıca aynı grafikte, bir periyot boyunca üç farklı ana ait olan serbest yüzey dağılımları görülmektedir. Gri bölgeler ise, rahatlama bölgelerini göstermektedir. Sonuçlar incelendiğinde; arzu edilen dalga profilinin elde edildiği, faz kayması etkilerinin ihmal edilebilir düzeyde olduğu ve dalgaların başarıyla sönümlendiği görülebilmektedir.

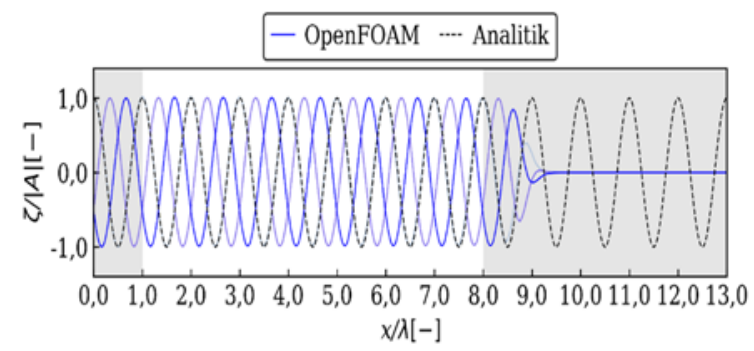

Şekil 11. Sayısal dalga kanalı problem bölgesi

\subsection{Dalga-Bariyer Etkileşimi}

Şekil 2'de şematik gösterimi verilen bariyer, dalga üreteci testinde doğruluğu sinanan rahatlama bölgeleriyle birlikte çözümlemeye dahil edilmiştir. Dalgaların bariyerden yansıma/iletilme karakteristikleri, çeşitli dalga frekansları için incelenmiştir. Dalga sayısı, 0,2-1,4 aralığında, 0,2 artımlarla değiştirilmiştir. Bariyer, su içine batık uzunluğu $a / h=0,1$ olacak şekilde, kanalın tam ortasına konumlandırılmıştır. Rahatlatma bölgeleri ile bariyer arasındaki mesafeler, bariyerden yansıyan ve iletilen dalgaların incelenebilmesi için yeterli uzunlukta modellenmiştir. Şekil 6'da verilen bloklama mantığı korunarak, bariyer ertafinda bir dalga boyu $\lambda$ uzunluğunda Şekil 12'deki gibi ek bloklar ağ örgüsüne dahil edilmiştir. Burada II ve III bloklarında oldukça küçük elemanlar kullanılarak bariyer etrafinda su hareketinin iyi çözümlenebilmesi sağlanmıştır. I ve IV blokları ile III ve III blokları arasındaki elemanların geçişi 1,05 büyüme oranı ile tanımlanmıştır.
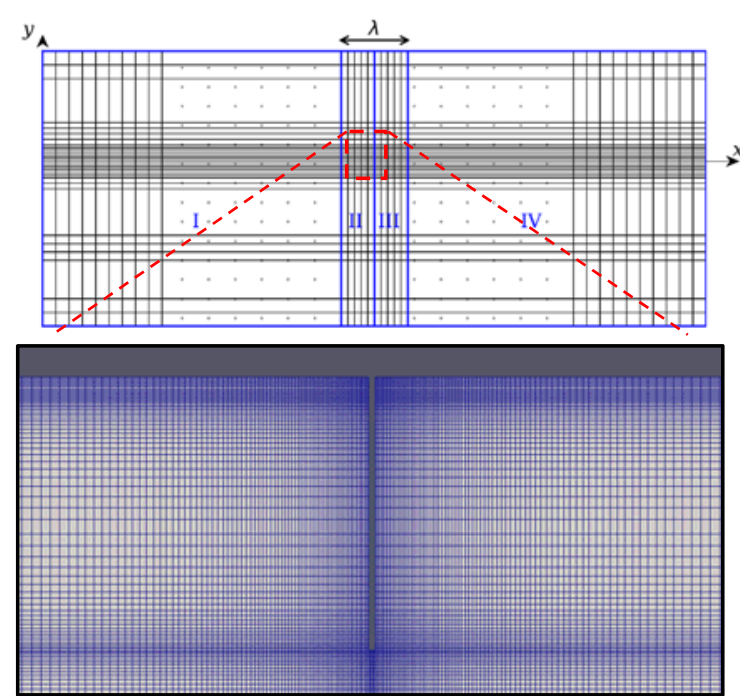

Şekil 12. Bariyer etrafında ağ örgüsü

Sekil 13'te, 29T-30T zaman diliminde, eşit zaman aralıklı 30 adet su yüzeyi dağılımı üst üste bindirilmiştir $(k a=0,4)$. Daha önce olduğu gibi gri bölgeler, rahatlatma bölgelerini göstermektedir. Sonuçlar incelendiğinde, dalga üreteci tarafındaki rahatlatma bölgesinin de istenen fonksiyonu sağladığı, böylece bariyerden yansıyan dalgaların burada sönümlendiği görülmektedir. Ayrıca, bariyerin altından iletilen dalgaların diğer uçta sönümlenmesi neredeyse bir dalga boyu mesafede başarıyla tamamlanmıştır. Bariyerden yansıyan dalgaların, üreteçten gelen dalgalar ile girişimi sebebiyle, $\quad x<0$ 'da genlik artışının olduğu görülmektedir. İletilen dalgaların genliği ise, üreteçten çıkan dalga genliğinden daha azdır. 
Kısmen Batık Bir Bariyerin Su Dalgaları ile Etkileşiminin Açık Kaynaklı Hesaplamalı Akışkanlar Dinamiği ile Incelenmesi

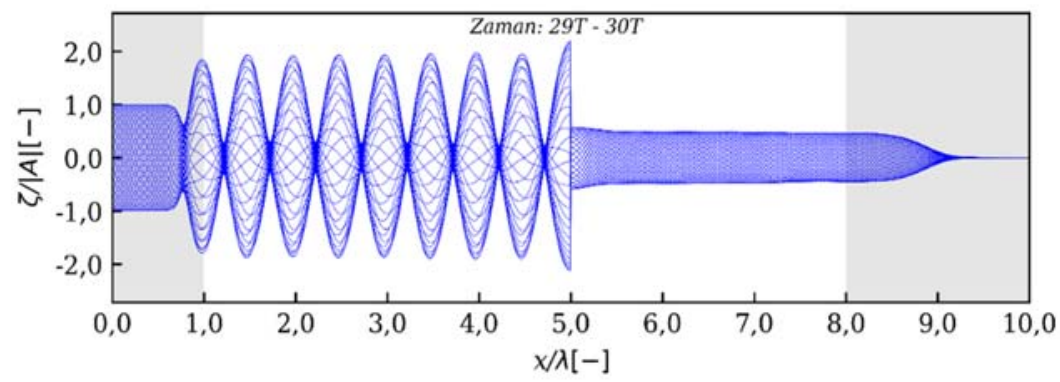

Şekil 13. Dalga-bariyer etkileşimi problem bölgesi ve sınır koşulları $(k a=0,4)$ (Görselde rahatlama bölgesinin son $3 \lambda$ uzunluğu gösterilmemiştir)

Sayısal olarak bulunan dalga karakteristiklerinin nicel olarak değerlendirilebilmesi için Eşitlik 4 ve 5 ile verilen katsayıların hesaplanması gereklidir. Başlık 4'te verilen yöntem ile $H_{\min }$ ve $H_{\max }$ değerleri belirlenmiş, $R$ ve $T$ katsayıları bulunmuştur.

Şekil 14'te yansıma ve iletilme katsayıları, analitik olarak hesaplanan değerler ile karşılaştırılmaktadır. Ayrıca bu şekilde, Stiassnie ve arkadaşları [20] tarafindan verilen deneysel sonuçlar da görülmektedir. Deneyde, $27 \mathrm{~m}$ uzunluğunda, $60 \mathrm{~cm}$ genişliğine ve 1,3 m derinliğinde bir dalga kanalı, piston tipi dalga üreteci ile donatılmıştır. Tankın sonunda dalgaların sönümlenebilmesi için pürüzlü 1:3 eğimli bir yüzey kullanılmıştır. Farklı boylarda bariyer üreteçten $14 \mathrm{~m}$ uzağa yerleştirilmiştir. Bariyerin önünden ve arkasından alınan ölçümlerle yansıyan, iletilen ve tankın sonunda sönümlenen dalga genlikleri ölçülmüştür [21]. Buna göre, geniş bir frekans aralığında HAD ile bulunan katsayıların, analitik ve deneysel çözümler ile nicel ve nitel uyuma sahip oldukları ortaya konmuştur. Problemdeki dalga karakteristikleri incelendiğinde, dalga frekansı arttıkça dalga yansımasının arttığı, dalga iletilmesinin de azaldığ 1 görülmektedir. Hatta, bariyerin suya batıklığı görece küçük $(\mathrm{a} / \mathrm{h}=0,1)$ olmasına rağmen, yüksek frekanslarda, dalgaların neredeyse tamamı yansitılabilmektedir. Buna karşılık, küçük dalga frekansları için dalgaların neredeyse tamamının bariyerden geçtiği ve çok azının yansıtılabildiği görülmektedir. Özetle, bariyerin yansıtma yeteneği, dalga frekansına bağlı değişmektedir.

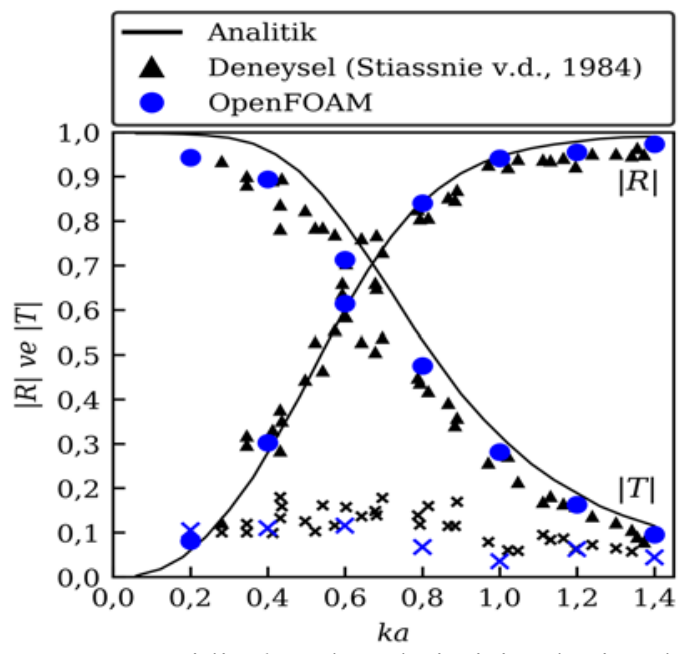

Şekil 14. Çeşitli $k a$ değerleri için bariyerden yansiyan $[R]$ ve iletilen [T] dalga katsayıları ("x" ile işaretli değerler kayıpları gösterir).

Lineer teorinin sürtünmesiz ve dönümsüz akışkan için türetilmiş olmasından ötürü, bariyer üzerindeki kayma gerilmeleri ve bariyer alt ucundaki çevri oluşumları göz ardı edilmektedir. Bir diğer deyişle enerji kayıpları göz ardı edilmektedir. HAD simülasyonlarında ise, bu etkiler dikkate alınmaktadır. Söz konusu enerji kayıpları için, Eşitlik 17 yardımıyla

$K=1-|R|^{2}-|T|^{2}$

değeri tanımlanabilir. Şekil 14'te bu değer incelenen frekanslar için hesaplanmış ve deneysel sonuçlarla karşılaştırmalı olarak verilmiştir (" $x$ " ile işaretli değerler). Genel olarak uyumlu bulgular 
1şı̆̆ında, ele alınan probleme ilişkin, viskozite etkilerinin de hesaba katıldığı, yüksek doğruluklu hesaplamaların yapılabildiği görülmüştür.

Söz konusu kayıpların çevrinti oluşumu ile ilişkisini ortaya koymak için, HAD ile elde edilen hız alanından çevrinti (vortisite) değerleri hesaplanmıştır. Şekil 15 'te, $\mathrm{ka}=0,4$ değerinde ve $\mathrm{t}=30 \mathrm{~T}$ anında çevrinti şiddeti dağılımı görülmektedir. Sonuçlara göre, çevrinti oluşumu bariyer alt ucunda gerçekleşmekte ve daha sonra çevriler (vorteksler) dalga hareketi ile taşınarak difüzyona uğramaktadır. Çevrinti oluşumunu ve çevri bölgelerinin hareketini görselleştirmek analitik yöntem ile olanaksız, deneysel yöntem ile çok zahmetlidir. $\mathrm{Bu}$ noktada HAD simülasyonlarının önemli avantaj oluşturduğu ortadadir.

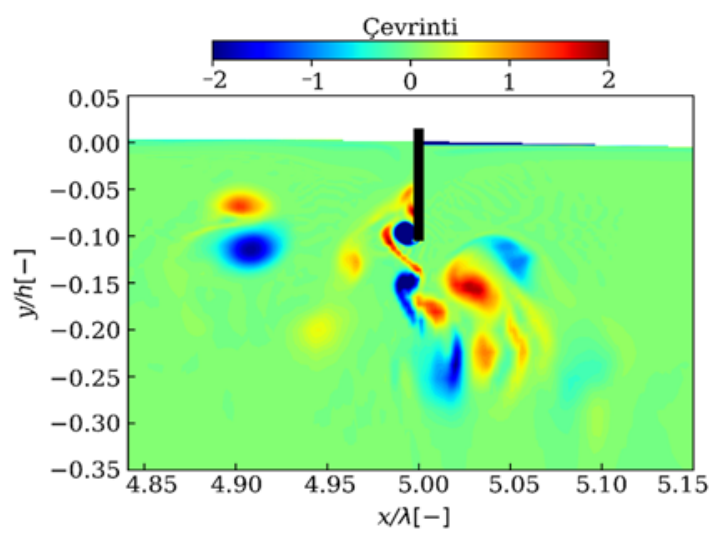

Şekil 15. $k a=0,4$ için çevrinti dağ 1 lımı

Salınan su sütunu tipi enerji dönüşüm makinalarında türbinden geçen havanın hacimsel debisi, ön duvar batıklığına ilişkin yansıma katsayısı R'ye bağlıdır [1,2]. Bu da enerji dönüşüm verimini doğrudan etkilemektedir. $\mathrm{Bu}$ sebeple bu uygulamalarda sahanın hakim dalga karakteristiklerinin dikkate alınarak boyutlandırma yapılması gereklidir. Buna göre, Şekil 2'de salınan su sütunu hidrodinamik veriminin analitik ve deneysel çalışmaları arasındaki farkın irdelenmesi için Şekil 3b'de şematik gösterimi verilen salınan su sütunu saçılım problemi çalışmanın bu bölümünde ele alınmıştır. Deneysel çalışmayla [4] uygun bir şekilde, bariyer batıklık oranı $\mathrm{a} / \mathrm{h}=0,163$, salınan su sütunu derinlik oranı $\mathrm{b} / \mathrm{h}=0,696$ değerinde tanımlanarak geometri düzenlenmiş ve sayısal dalga tankında RB2 bölgesi ortadan kaldırılmıştır. Birimsiz dalga sayısı kH'ın 0,6 ile 3,4 arasında değiştirilmesi ile gerçekleştirilen simülasyonlar sonrası Bölüm 4'te verilen yöntem ile $H_{\min }$ ve $H_{\max }$ değerleri belirlenmiş ve $R$ katsayısı bulunmuştur. $\mathrm{Bu}$ problemde $\mathrm{T}$ katsayısının söz konusu olmadığı dikkat alınarak, salınan su sütununda saçılım kaynaklı enerji kaybı bulunmuş ve $\mathrm{K}_{\mathrm{S}}$ ile ifade edilmiştir.

Şekil 3c'de şematik gösterimi, Şekil 6 ve Şekil 12'de ağ yapısı verilen kısmen batık bariyerli sayısal dalga tankından bariyer batıklık oranı $\mathrm{a} / \mathrm{h}=0,163$ için simülasyonlar gerçekleştirilmiş, bariyer çevresindeki enerji kayıpları Eşitlik 17 ile elde edilerek $K_{B}$ ile ifade edilmiştir.

Şekil 2'de salınan su sütunu hidrodinamik veriminin analitik ( $\left.\eta_{\text {Analitik }}\right)$ [1] ve deneysel ( $\left.\eta_{\text {Deneysel }}\right)$ [4] değerleri arasındaki fark (Eşitlik 18),

$\Psi=\eta_{\text {Analitik- }} \eta_{\text {Deneysel }}$

ile ifade edilmiştir. Böylece, bariyer alt ucundaki çevri oluşumları sebebiyle oluşan enerji kayıpları, diğer bulgularla birlikte birimsiz dalga sayısına bağlı olarak grafiğe dökülmüştür. Şekil 16'da enerji kaybı eğrilerinin belirgin bir uyum içinde olduğu görülebilmektedir. Analitik ve deneysel çalışmalarında elde edilen hidrodinamik verim farkı, $\Psi$ 'nin dalga özelliklerine göre \%20-40 gibi oldukça yüksek oranlarda değiştiği görülmektedir.

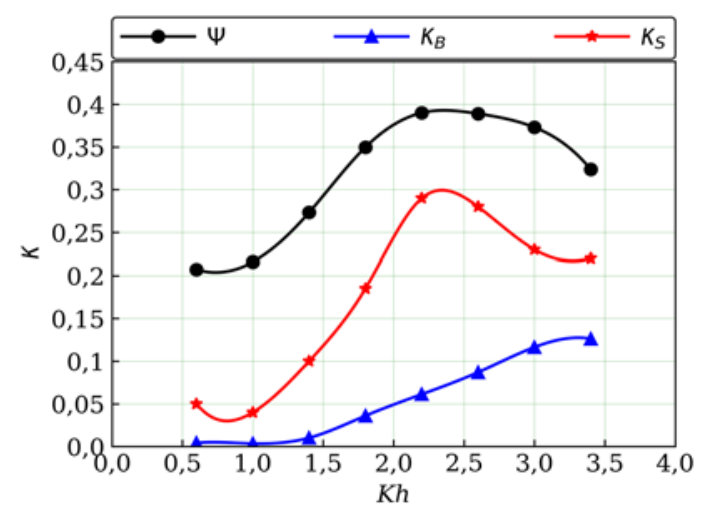

Şekil 16. Salınan su sütunu saçılım probleminde enerji kaybı analizi sonuçları 
Saçılım probleminden ortaya çıkan enerji kaybı $K_{S}$, beklendiği gibi $\Psi$ 'nin altında kalmış ve dalganın özelliklerine bağlı olarak $\Psi$ ' ye göre daha fazla değişim göstermiştir. $\mathrm{Bu}$ değerler, deneysel hidrolik verimlerin analitik hesaplamalara göre düşük çıkmasında, saçılım probleminin önemli bir yer tuttuğunu göstermektedir. $K_{S}$ ' nin en yüksek değerlere ulaştığı durumlarda, $\Psi$ 'nin de en yüksek değerlerde olduğu görülmekteydi. $K_{B}$ ise bu değişimden etkilenmemiş, çalışmasının önceki bölümündeki tespitlerle uyumlu bir değişimle elde edilmiştir. Bariyer etrafındaki enerji kayıpları, kayıpların bu denli artışının önemli bir etkenidir. Bu problemde $K_{B}$, dalga özelliklerine göre değişlik göstererek kaybın \%1-13'ünü oluşturmuş bulunmaktadır.

\section{SONUÇ}

$\mathrm{Bu}$ çalı̧̧mada, bir salınan su sütunu cihazının ön duvarı olan kısmen batık, düşey, düzlemsel bir bariyerin su dalgaları ile etkileşiminin söz konusu olduğu temel bir problem ele alınmış ve sayısal olarak incelenmiştir. Açık kaynaklı hesaplamalı akışkanlar dinamiği yazılımı olan OpenFOAM bünyesindeki waves $2 F o a m$ modülü yardımıla sayısal çözümlemeler yapılmıştır. $\mathrm{Bu}$ modül kapsamında yer alan dalga oluşturma ve dalga sönümleme gibi fonksiyonların ön testleri için, iki boyutlu bir kanalda küçük genlikli dalgaların ilerlemesi problemi ele alınmıştır. Sonuçlar, analitik çözümlerle karşılaştırmalı olarak sınanmış, yeterli doğruluğa sahip sonuçlar elde edilmiş, uygun ağ ve çözücü özellikleri belirlenmiştir. Daha sonra dalga-bariyer etkileşimi problemine geçilmiştir. Sayısal simülasyonlarla, bariyerden yansıyan ve iletilen dalgaların genliklerine ilişkin hidrodinamik katsayıların dalga frekansına bağlı değişimi hesaplanmıştır. Bariyerden yansıyan dalgalar ile üreteçten gelen dalgaların ayrıştırılması da bu süreçte gerçekleştirilmiş̧ir. Bulgular, analitik ve deneysel sonuçlar ile uyuma sahiptirler. Ayrıca, viskoz etkilerin de hesaba katılmasından ötürü, bariyerdeki enerji kayıplarının irdelenmesi yapılmış ve bariyer alt ucundaki çevri oluşumu görselleştirilmiştir.

Çalışmada ayrıca salınan su sütununda enerji kayıpları ve nedenleri irdelenmiş, salınan su sütununda saçılım kaynaklı enerji kayıpları ve bariyer çevresindeki enerji kayıpları sayısal olarak elde edilmiştir. Bariyer çevresindeki enerji kayıplarının özellikle yüksek dalga sayılarında arttığ1 görülmüş olup, salınan su sütunu uygulamalarında sahanın hakim dalga karakteristiklerinin dikkate alınarak boyutlandırma yapılmasının gerekliliği gösterilmiştir.

$\mathrm{Bu}$ çalışmada yeterli doğruluğa sahip sonuçlar ürettiği görülen araştırma yöntemi ile, daha karmaşık ve gerçekçi yapıların dalga karakteristikleri belirlenebilir. waves2Foam modülü kapsamında yüksek mertebeden dalga teorilerine dayalı dalga oluşturma özellikleri mevcut olup, bunlar, laboratuvar ölçeğinde gerçekleştirilen deneysel yöntemleri bütünleyici araçlar olarak kullanılabilir. Özellikle, deneylerde tespit edilmesi zahmetli olan cisimler etrafindaki çevri oluşumu ve taşınımına iliş̧kin, HAD ard-işlemleri ve görselleştirme araçlarının önem taşıdığı görülmüştür.

\section{KAYNAKLAR}

1. Evans, D.V., Porter, R., 1995. Hydrodynamic Characteristics of an Oscillating Water Column Device. Applied Ocean Research, 17(3), 155-164.

2. Şentürk, U., Özdamar, A., 2012. Wave Energy Extraction by an Oscillating Water Column with a Gap on the Fully Submerged Front Wall. Applied Ocean Research, 37, 174-182.

3. Manasseh, R., Mcinnes, K., Hemer, M., 2017. Pioneering Developments of Marine Renewable Energy in Australia, The International Journal of Ocean and Climate Systems, 8, 50-67.

4. Morris-Thomas, M., Irvin, R.J., Thiagarajan, K.P., 2007. An Investigation into the Hydrodynamic Efficiency of an Oscillating Water Column, Journal of Offshore Mechanics and Arctic Engineering, 129, 273-278.

5. Ning, D.Z., Wanga, R.Q., Zou, Q.P., Teng, B., 2016. An Experimental Investigation of Hydrodynamics of a Fixed OWC Wave Energy Converter, Applied Energy, 168, 636-648.

6. Zhang, Y., Zou, Q.P., Greaves, D., 2012. Airwater Two-phase Flow Modelling of 
Hydrodynamic Performance of an Oscillating Water Column Device, Renewable Energy, 411, 59-170.

7. Ning, D.Z., Wanga, R.Q., Zou, Q.P., Teng, B., 2015. Investigation of Hydrodynamic Performance of an OWC (Oscillating Water Column) Wave Energy Device Using a Fully Nonlinear HOBEM (Higher-order Boundary Element Method), Energy, 83, 177-188.

8. Ursell, F., 1947. The Effect of a Fixed Vertical Barrier on Surface Waves in Deep Water, Mathematical Proceedings of the Cambridge Philosophical Society, Cambridge University Press, 43(3), 374-382.

9. Mei, C.C., Black, J.L., 1969. Scattering of Surface Waves by Rectangular Obstacles in Waters of Finite Depth. Journal of Fluid Mechanics, 38(3), 499-511.

10. McIver, P., 1985. Scattering of Water Waves by Two Surface-Piercing Vertical Barriers. IMA Journal of Applied Mathematics, 35(3), 339-355.

11. Porter, R., Evans, D.V., 1995. Complementary Approximations to Wave Scattering by Vertical Barriers. Journal of Fluid Mechanics, 294, 155-180.

12. Jacobsen, N.G., Fuhrman, D.R., Fredsøe, J., 2012. A Wave Generation Toolbox for the Open-Source CFD Library: OpenFOAM $\AA$. International Journal for Numerical Methods in Fluids, 70(9), 1073-1088.

13. Kamath, A., Chella, M.A., Bihs, H., Arntsen, Ø.A., 2015. CFD Investigations of Wave Interaction With a Pair of Large Tandem Cylinders. Ocean Engineering, 108, 738-748.

14. Kamath, A., Bihs, H., Arntsen, Ø.A., 2015. Numerical Modeling of Power Take-off Damping in an Oscillating Water Column Device. International Journal of Marine Energy, 10, 1-16.

15. Vukčević, V., Jasak, H., Malenica, Š., 2016. Decomposition Model for Naval Hydrodynamic Applications, Part II: Verification and Validation. Ocean Engineering, 121, 76-88.

16. Dean, R.G., Dalrymple, R.A., 1991. Water Wave Mechanics for Engineers and Scientists, World Scientific Publishing Co Inc, Singapore.
17. Mei, C.C., Stiassnie, M., Yue, D.K.P., 1989. Theory and Applications of Ocean Surface Waves: Part 1: Linear Aspects, World Scientific Publishing Co Inc, Singapore.

18. Chakrabarti, S.K., 1987. Hydrodynamics of Offshore Structures. Springer, Berlin.

19. Ubbink, O., 1997. Numerical Prediction of Two Fluid Systems with Sharp Interfaces, Doktora Tezi, Imperial College.

20. Stiassnie, M., Naheer, E., Boguslavsky, I., 1984. Energy Losses Due to Vortex Shedding From the Lower Edge of a Vertical Plate Attacked by Surface Waves. Proceedings of the Royal Society of London A: Mathematical, Physical and Engineering Sciences, 396(1810), 131-142.

21. Knott, G., Flower, J., 1979. Wave-tank Experiments on an Immersed Parallel-plate Duct. Journal of Fluid Mechanics, 90(2), 327-336. 
